\title{
Barefoot and Rosary-in-Hand: A Geography of Pilgrimage in Ireland
}

\author{
Richard Scriven
}

Department of Geography, UCC

Pilgrimage is one of the fundamental structures a journey can take - the quest in search of something, if only one's own transformation, the journey toward a goal. Rebecca Solnit, Wanderlust: A History of Walking

\section{Departure}

Bare feet treaded carefully on gravel. Staves sounded rhythmically against the path. Backpacks, filled with diluted orange drinks and sandwiches, were tightened on backs. The pilgrimage had begun. Just after dawn on 'Reek Sunday', the last Sunday in July 2012, I had started my climb of Croagh Patrick along with thousands of other pilgrims from across Ireland and further afield. Toddlers and octogenarians, whole families and groups of friends, youth clubs and lone walkers, all merged into one in the ascent of this conical peak in Co Mayo. We were participating in the continuation of ancient customs stretching back millennia, although the modern pilgrimage centres on the belief that St Patrick spent 40 days in prayer on the summit. As each person embarked on the journey up the mountain, they became a 'pilgrim'. Simultaneously, their beliefs, emotions and performances imbued the mountain with significance and sacredness. The place defines the people and the people define the place: people becoming pilgrims, a mountain becoming a sacred space. My research is about pilgrimage and this dynamic process that shapes the people and places involved.

\section{Understanding Pilgrimage}

From the car park at Murrisk, a well-established path winds its way up the ridge on the southern shore of Clew Bay towards the 'Reek', as Croagh Patrick is known locally. As the path stretches out before me, I paused to take in the crowds flowing up and down the hillside: children holding on to their parents, rosary beads swinging gently in hands, weary pilgrims leaning on their staves for support.

Croagh Patrick, recognised as being one of the best examples of large scale traditional pilgrimage in Western Europe, reminds us of the continuing role of pilgrimage in the contemporary world. In recent decades, with improved transport systems and increased 


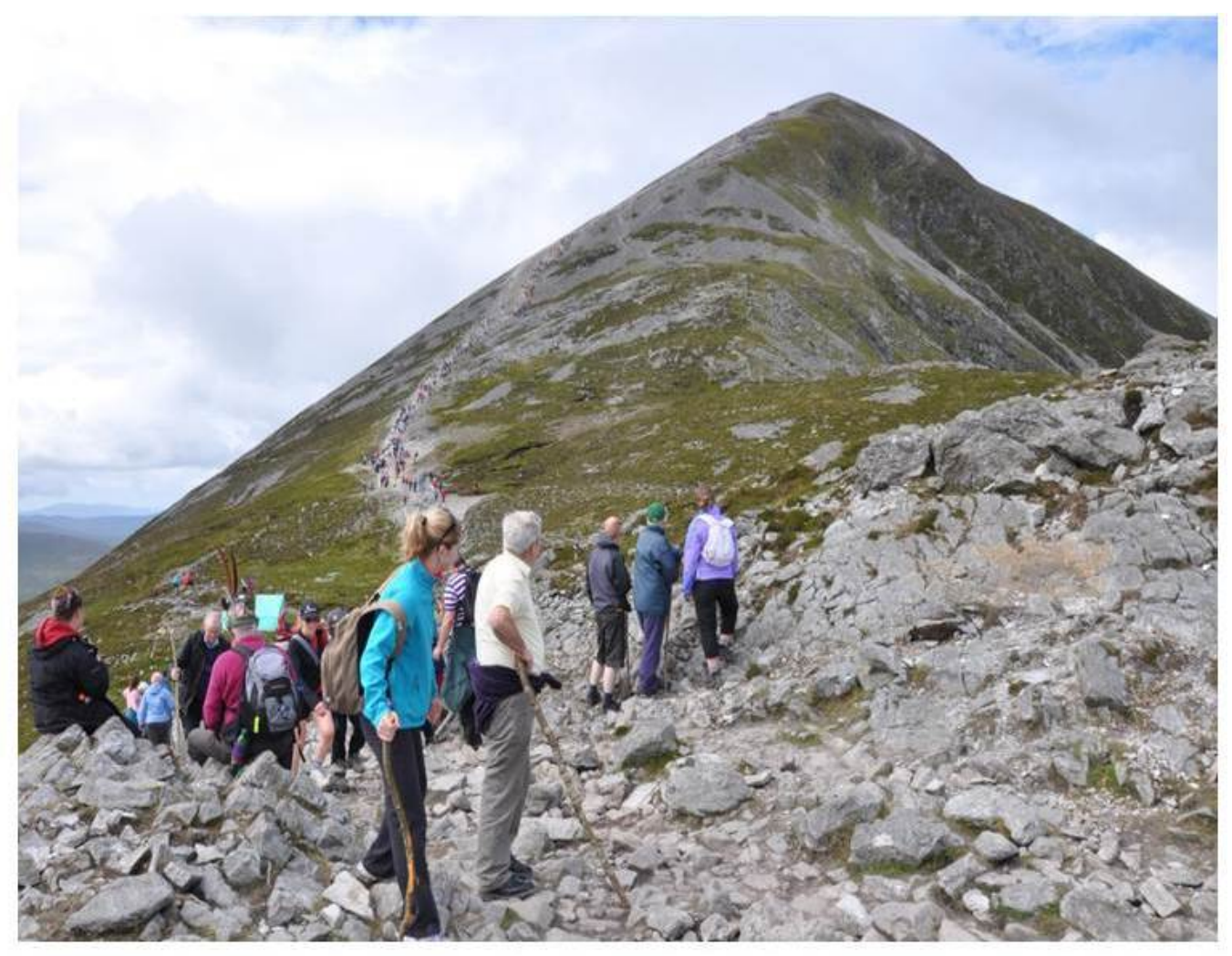

Figure 1: Pilgrims looking back at Croagh Patrick on Reek Sunday 2012. The long line of hundreds of pilgrims climbing and descending the mountain can clearly be seen. Image: Richard Scriven.

living standards, this practice has witnessed a revitalisation. This year up to 5 million Muslims will make the Hajj to Mecca, 20 million Catholics will go to Guadalupe in Mexico, and over 30 million Hindu pilgrims will travel to the River Ganges. In Ireland, Christian pilgrims will visit other major sites across Ireland, such as Knock and Lough Derg, and a range of regional and local shrines, especially holy wells.

Why is this ancient practice still attracting millions of people? What is its continuing appeal? In its essence, pilgrimage is a journey. Physically, it involves travelling and undertaking challenges, such as walking certain routes, prayer patterns and fasting or keeping vigil. Spiritually and emotionally, the journey offers a chance to take a break from the hustle and bustle of the everyday world and reflect on the more meaningful things in life. In particular, there is a strong desire to go in search of authentic experiences in specific sacred or special sites. The totality of the journey can be a transformative event, with the pilgrim returning home renewed, with a new outlook on life. All of these elements combine, to continually draw people to leave their homes and go on pilgrimage. 


\section{Approaching Pilgrimage}

Before going on pilgrimage, the pilgrim must make preparations, select clothing and equipment. Similarly, the researcher must prepare a toolkit. This 'toolkit' consists of concepts and methods. I study pilgrimage as a geographer. Human geography investigates how people, through their actions and ideas, shape the world around them and how environments influence and define people. Therefore, I am interested in pilgrimage as an activity that shapes the way people and places interact.

An ethnographic methodology is the way I conduct my research. It involves observer participation and interviews with pilgrims. By being present at the pilgrimages and participating with and alongside other people, I can get a first-hand appreciation of all that is involved. I use cameras and camcorders to capture the performances and events of the pilgrimage. This observer participation is complemented by interviews. Discussions with people about their motivations and experiences, allows for explorations of the meanings and significance of pilgrimage. During my conversations with pilgrims we talk about why they go on pilgrimage, how they find the experience and what it means to them. In combining my geographical concepts and the rich audio-visual materials produced in fieldwork, I can provide new insights and appreciations of the role of pilgrimage in Irish society.

\section{Journeys and Paths}

The path up the Reek is a steep climb over loose rocks and gravel (see Figure 2). It is often said that, on the Reek, for every one step forward you slip back two. During my research, I stop to watch and photograph the progress of the pilgrims. I can see determination, doubt and exhaustion. The multitude of motivations and feelings are matched only by the countless steps taken up and down the mountain that day.

Traditionally, pilgrimage was about the desire to encounter the divine, to do penance or to gain some favour. It is now appreciated that these religious reasons are complemented by a vast array of spiritual, emotional and personal motivations. Pilgrims bring all manner of concerns, sentiments and feelings to the pilgrimage. Sick people, departed loved ones and current hardships have been all mentioned as reasons for climbing.

Several of the pilgrims expressed a strong connection between the physical journey and their intentions for being there. Turlough, a middle-aged man, explained that he thought of "family, friends and those in need while walking, often reciting simple prayers of childhood for their intentions". A comparable sentiment was expressed by Lily, a young woman who went with her family: "I've always found that praying while I walk helps so much. It keeps my mind off the hard task and reminds me of why I am doing it." The greater mean- 


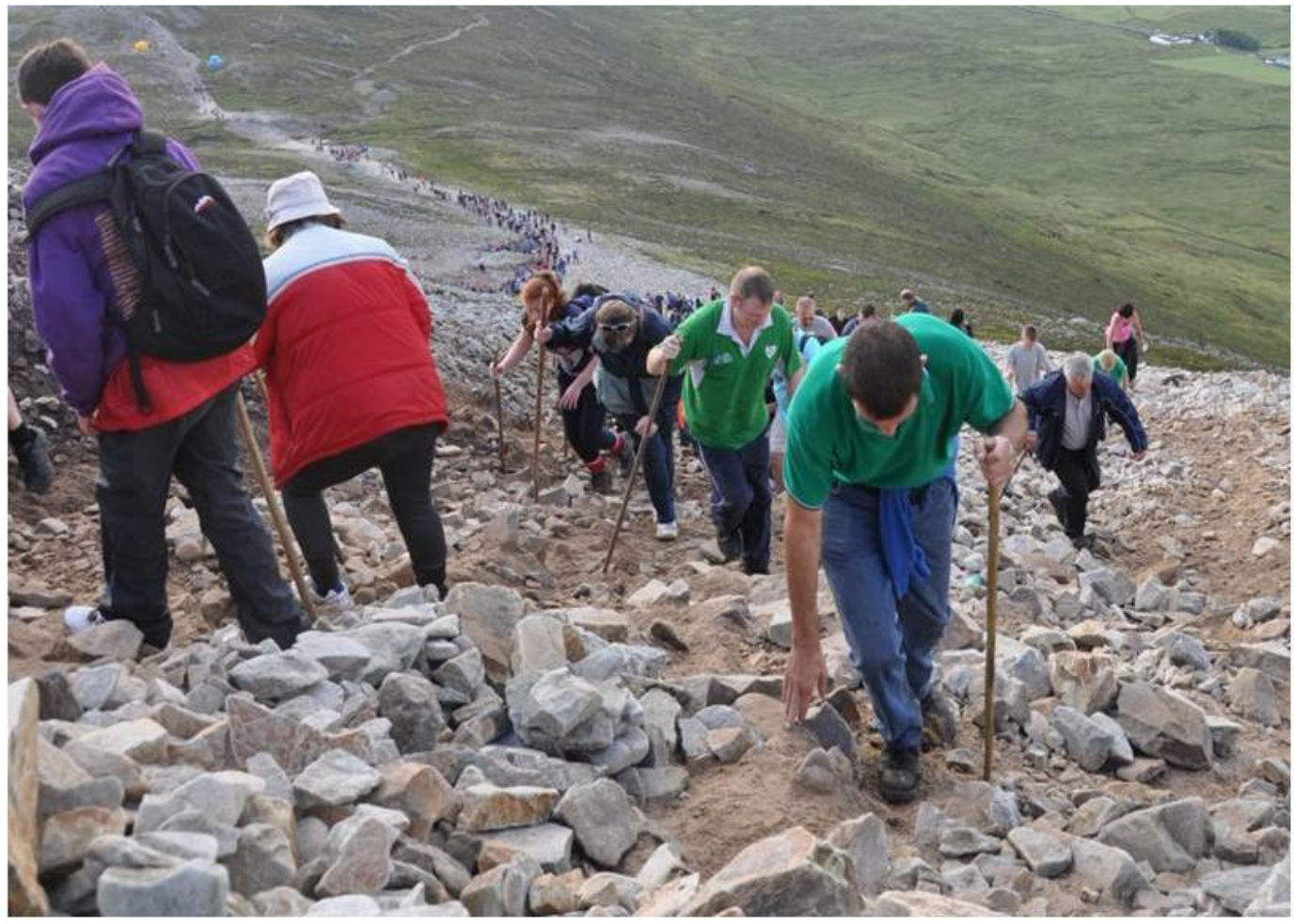

Figure 2: The steep path and loose rocks make the trek up 'the Reek' particularly challenging for pilgrims. Each pilgrim struggles up the path bringing their own intentions and concerns with them. Image: Richard Scriven.

ing of the route and the trek was mentioned by Ciarán, an older man, who commented that "[the path] tells you that anyone that wants to do the climb must do it the hard way and some people suffer because of it each year."

The trail up the side of the Reek is alive: alive with movement and activity, but equally with purpose and feeling. By going on pilgrimage, each person participates in and becomes embedded in this process. Each pilgrim weaves her or his own path. With every step the physical exertions of the climb are blended with the very personal intentions and emotions of the pilgrimage.

\section{Barefoot Pilgrims}

One of the customs most associated with Croagh Patrick is climbing barefoot. Only a small minority now undertake this challenge. It is most common to find people doing it because they feel it is in the spirit of the pilgrimage; however, some are doing it for specific reasons, such as a charitable cause or religious concerns. The barefoot pilgrims frequently make reference to the kind words and support from fellow pilgrims. Kate, a middle aged woman, explained that such encouragement made a significant difference to her on her climb: “There's a great sense of camaraderie and kindness, it's been really 


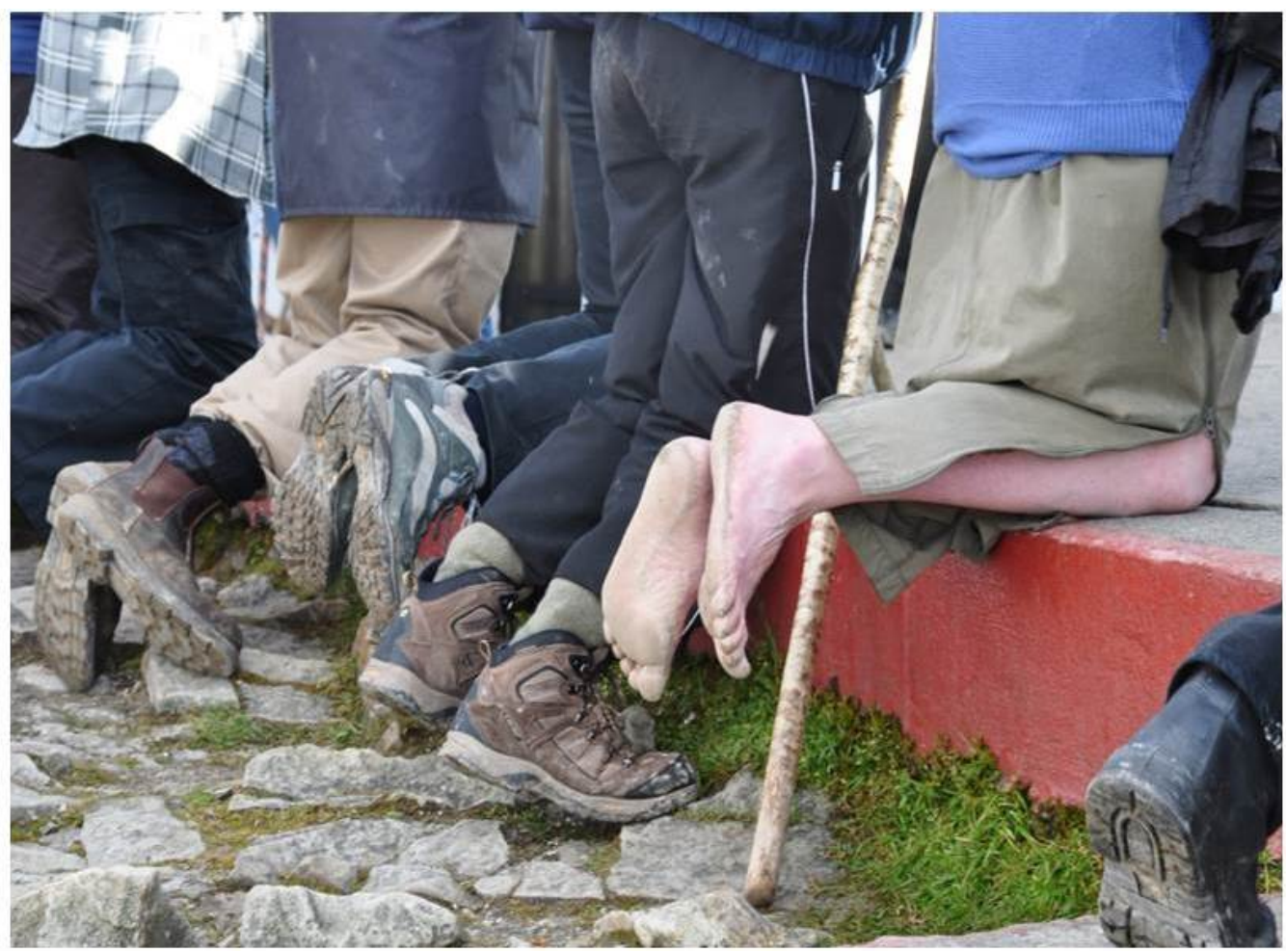

Figure 3: A barefoot pilgrim kneels among those praying by the chapel after mass on the summit. Image: Richard Scriven.

fantastic, because it's the hardest physical thing I have ever done".

\section{The Reek: A place apart}

"We're there!" a woman announced triumphantly to her companions. They were relieved and delighted to have reached the summit of the Reek. For many pilgrims, there are other observances to be followed. Large crowds attend the frequent open-air masses and go to confession, some say the rosary while circling the mountain-top chapel. Pilgrims then take a well-earned break with the packed lunch and maybe a cup of tea or soup from one of the stalls set up for the day. There is a festive atmosphere. This is a special occasion where something unique happens in many different ways each year.

It is important to acknowledge the role of the location and the people in constructing this event. Firstly, the peak top sitting at 764 metres $(2,507 \mathrm{ft})$ creates a feeling of being separate from the rest of the world. It was this feature that is thought to have brought St Patrick here, so that he could withdraw in prayer and meditate. Indeed, it still resonates today, with one pilgrim, Anthony saying that for him "travelling to a sacred place, is so important because it allows me to be connected spiritually with my God". Secondly, the large gathering and the chapel on the mountain-top site are most unusual, especially in an Irish context where most elevations are largely devoid of people and human-made 
features. In addition, there is a distinct convivial character with many of the normal social barriers being removed. All pilgrims, friends and strangers alike, swap stories and even share food.

\section{Return}

The descent marks a slow return to the everyday world. Pilgrims are jubilant: the most arduous part of the day is behind them, they have filled up on lunch and, some, have attended mass and got confession. The breaks on the way down are not breathless pauses, but stops to take in the view or to offer a few words of encouragement to those coming up. As we leave the Reek, we are returning to normal life and shedding the role of pilgrims. However, we have been part of something which has left marks both on us and on the mountain.

By performing the pilgrimage, observing events and talking with people, I explore the rich and multifaceted relationships that exist between people and places. I also tell these people's stories and tell the story of this special mountain. This contributes to our understandings and appreciations of places such as Croagh Patrick and the customs involved. Furthermore, it presents a distinct way of valuing the experiences of each individual and our continuing role in shaping and preserving our cultural heritage and natural landscape.

Thanks to my supervisors John Crowley and Ray O'Connor, and the staff and fellow research postgraduates in the Department of Geography. Also, thanks to my family and friends for their support. My research is funded by the Irish Research Council Government of Ireland Postgraduate Scholarship and was previously funded under the Department of Geography $\mathrm{PhD}$ Studentship Scheme. Some of my fieldwork was funded by the Geographical Society of Ireland Postgraduate Fieldwork/Travel Award 2013. All the images were taken during my fieldwork on Reek Sunday 2012 and 2013. 